\title{
O TEMPO DESORIENTADO TEMPO E HISTÓRIA "COMO ESCREVER A HISTÓRIA DA FRANÇA?"
}

François Hartog

"A França deve recompor seus anais a fim de adaptá-los aos progressos da inteligência." Esta fórmula de Chateabriand, no prefácio de seus Études Historiques, poderia figurar como epígrafe dos Lieux de mémoire de Pierre Nora. A situação, evidentemente, não era a mesma, mas para Chateaubriand, depois de 1830 , assim como para Nora, no início dos anos 80, tratava-se de partir de um diagnóstico sobre o presente e de registrá-lo. Para reconstruir "sobre um novo plano", dizia Chateaubriand, para se questionar, previamente, o que significa "recompor", no caso de Nora: "Como escrever a história da França" ?

O momento dos Lieux de mémoire (1984-1993) são, com efeito, os anos 80 . O projeto concebido antes de 1989 foi concluído depois. Caso se pense no Bicentenário da Revolução, a queda do muro de Berlim, com a qual ninguém sonhava, pegou todo mundo de surpresa. Ele situa, portanto, dos dois lados de 1989. Ele acompanha, registra e reflete a onda de memória que, a partir da metade dos anos 70, espalhou-se sobre a França. ${ }^{2}$ Basta mencionar, dentre múltiplos testemunhos possíveis, o filme "Le chagrin et la pitié" (1971), o livro de R. Paxton sobre Vichy (1972), Le Cheval d'orgueil (1977), de P. Jakez Hélias, Le Syndrome de Vichy de H. Rousso (1987), Les assassins de la mémoire (1987) de P. VidalNaquet ou, sob um outro registro, a ativa renovação dos centros históricos das cidades, a proliferação dos ecomuseus ou a riqueza do tema do Patrimônio. Mas, de Chateaubriand a Nora, pode-se, imediatamente, observar uma diferença na relação de tempo: o "novo plano", convocado pelos "progressos" da inteligência, remetia a uma visão do tempo como progresso. Tratava-se do tema da perfectibilidade. Ao passo que, no mo-

François Hartog é Doutor de Estado pela Universidade de Paris e professor da École des Hautes Études en Sciences Sociales (Paris/France). A tradução do presente artigo foi gentilmente autorizadada pclo autor. Sua publicação original encontra-se em: Annales HSS, nov-déc., 1995, n.6, p.1219-1236. Tradução de Eliane Cezar. 
mento de começar aquilo que virá a ser os Lieux, Nora considera somente o presente: "o desaparecimento rápido de nossa memória parecia convocar um inventário de lugares onde ela se encarnou seletivamente".

Os Lieux de mémoire foram um trabalho coletivo, em uma escala. aliás, bastante excepcional na edição francesa. Fernand Braudel teve, ainda, a audácia de lançar-se em uma longa Histoire de la France solitária. como Michelet, mas, tendo partido muito mais tarde do que o último, ele não pôde explorar até o fim esta Identité da França, onde singularidade e permanência se encontram. OsLieux são, também, a obra de um historiador que nos dá sua "interpretação", no sentido musical da expressão, suas Recherches, senão (resguardadas as devidas proporções) sua Recherche da história da França. E, portanto, esta interpretação e o projeto cultural que a sustenta que eu gostaria de interrogar, privilegiando, dentre outras dimensões possíveis, aquela da relação de tempo.

\section{REGIMES DE HISTORICIDADE E ESCRITURAS DA HISTÓRIA}

"Nos tempora sumus", nós somos, nós mesmos, tempo. Esta expressão, de Santo Agostinho, é cômoda para recusar a idéia de um tempo que, tal como o tempo astronômico, ser-nos-ia puramente exterior, sobre o qual não poderíamos agir, tal como acontece, freqüentemente, com Braudel. Ainda na conclusão de "L Identité de la France", a longa duração é definida como uma "enorme superfície de água quase estagnante" que, insensivelmente, mas irresistivelmente, "arrasta tudo com ela".

Permitam-me, aqui, uma digressão e a introdução da noção de regime de historicidade. Eu o compreendo como uma formulação sábia da experiência do tempo que, em retorno, modela nossos modos de dizer e de viver nosso próprio tempo. Um regime de historicidade abre e circunscreve um espaço de trabalho e de pensamento. Ele ritma a escritura do tempo, representa uma "ordem" do tempo, à qual se pode subscrever ou, ao contrário (e mais freqüentemente), querer escapar, procurando elaborar uma outra. "Quando o passado não mais ilumina o futuro, o espírito caminha nas trevas." Esta frase, tomada de empréstimo de Tocqueville, ilumina, se assim posso dizer, meu propósito. Antes (quando o passado iluminava o futuro, quando a relação entre passado e futuro era regrada pela referência ao passado) era o tempo da historia magistra vitae. Quando, ainda em 1796, Chateaubriand pensava poder, "o brandão das revoluções passadas nas mãos, iluminar a noite das revoluções futuras", seu paralelo das revoluções antigas e modernas depende deste paradigma. ${ }^{3}$ Mas este 
antigo regime de historicidade se desfez. A Revolução marcou, na França, o retorno desta economia do tempo. A partir de então, não cabe mais ao passado esclarecer o futuro mas, ao contrário, cabe ao futuro esclarecer o passado. O próprio Tocqueville é testemunha, ele que, para compreender o passado recente da França, achava necessário fazer uma viagem no futuro, na América, para ali descobrir a nova sociedade. Ainda que, paradoxalmente na aparência, sua tese essencial consista em marcar a continuidade entre monarquia e Revolução.

Quais são as outras características do regime moderno de historicidade, tal qual ele se instalou entre o final do século XVIII e o início do século XIX? Reinhart Koselleck mostrou de que forma, a partir de 1860, formulou-se na Alemanha die Neuzeit, em ruptura com relação ao antigo regime de escritura da história organizado em torno da história mestra da vida. ${ }^{4}$ Nesta perspectiva, a Revolução Francesa, entre seus próprios atores e entre aqueles que tentaram explicá-la quase imediatamente, também pode ser lida como um conflito entre dois regimes de historicidade. Do ponto de vista da história, as características deste regime moderno, evidenciadas por Koselleck, são a passagem do plural die Geschichten para o singular die geschichte: a história, a História em si, que, no final, segundo a fórmula de Droysen, tornar-se-á "conhecimento de si mesma". Ela é concebida como processo, segundo a idéia de que os acontecimentos não mais ocorrem apenas no tempo, mas através (durch) dele.

As lições de história são substituídas pela exigência de previsões. $\mathrm{O}$ historiador não mais elabora o exemplar, mas ele busca o único. Na historia magistra, o exemplar ligava o passado ao futuro através da figura do modelo a imitar. Com o regime moderno, o exemplar, como tal, desaparece para dar lugar àquilo que não se repete. O passado está, por princípio, ultrapassado. O futuro, isto é, o ponto de vista do futuro domina: "A história se tornou, essencialmente, uma intimação endereçada pelo futuro ao contemporâneo". A intimaçāo, acrescentaria, a fim de completar esta fórmula de Julien Gracq, estendeu-se também ao passado e se impôs aos historiadores que, ao longo do século XIX, organizaram e conceberam sua disciplina como ciência do passado. Este futuro que esclarece a história passada, este ponto de vista e este telos que lhe dão sentido, adquiriu, sucessivamente, com as vestes da ciência, a imagem da Nação, do Povo, da República ou do Proletariado. Se ainda resta uma lição da história, ela vem, por assim dizer, do futuro e não mais do passado. Ela está em um futuro que acontecerá como diferente do passado, ao passo que a historia magistra repousava sobre a idéia de que o futuro não repetia o passado, porém não o excedia jamais (movia-se no interior 
do mesmo circulo, com as mesmas regras do jogo, a mesma providênc e os mesmos homens, partilhando a mesma natureza humana).

Quanlo icmpo durou a historia magistra? Segundo Koselleck, st dissoluçấo, ao menos como princípio explicativo e instrumento heurí tieo alivos, é dada entre o fïm do século XVIII c o início do século XI) enquanto sc elabora - na Alemanha, primeiramente - um conceito me derno de história. Quando ela começou? A fórmula remonta a Cícer mas os gregos praticaram esta forma de história desde o século IV a.C senão já no século V a.C., con Tucídides. ${ }^{5}$ Em seu princípio, esta hist ria relórica, concebida como coletânea de exemplos, era feita por quel se supunha fazer a história (os cidadãos, o homem político, o príncipe

Quanto ao regime moderno de historicidade, não se poderia inscr vê-lo entre estas duas datas simbólicas que săo 1789 e $1989 ? 1989$ nã poderia marcar o fim deste regime moderno ou, ao menos, uma forte ce sura em sua história? Esta hipótese, faz-se necessário esclarecer, nad tem a ver, evidentemente, com qualquer fim da história. Olhar Les liea de mémoire a partir de uma perspectiva larga ou de uma história de lor ga duraçầo das relaçóes de tempo, conduz a lê-los como uma expressãi se é que posso assim dizer, deste acabamento quase acabado e, lambén ou já como uma tentativa de a ele responder, fazendo dele história.

Uma tal hipótese nầo implica que o regime moderno năo tenha c nhecido questionamentos anteriormente, que ele nāo tenha tido "crises do tempo, numerosas. Ao contrário. Un regime de historicidade, com efe to, nấo é uma culidade metafísica, vinda do céu, mas um plano de pense mento de longa duraçáo, uma respiração, uma rítmica, uma ordem do tem po, que permite e próbe pensar certas coisas. Contestado tão logo de su instauraçâo, tum regime de historicidade reformula, "recicla" os elemen tos anteriores da relaçẩo de tempo, a fïm de fazer com que ele diga outr coisa, de outra mancira (tal como a historia magistra retomada pelo cris tianismo c pelos historiaderes medicvais). A passagem de um regime par outro conduz a periodos de cruzamentos: o periodo revolucionário é un bom exemplo. Um regime, finalmente, jamais existe cm estado puro.

Deste regime moderno, năo se trata de traçar a história ou os ava tares. Limito-me a indicar duas crises: seu questionamento contemporâ neo, ao qual me dedicarei um pouco, uma vez que ele fornece justamen te o contexto que tornou possível os Liezx, e, anteriormente, a profund crise que se manifesta por volta de 1914, já antes da guerra e, ainda mai depois, nos anos 20. Basta evocat, aqui, apenas um nome: 0 de Walte Benjamin que, entre 1920 e 1940, contra o historismus e aquilo que apa recia como a falência definitiva da filosofia hegeliana da história, pro 
curou formular um novo conceito de história, operando a partir de um outro tempo histórico (contra o tempo que ele caracterizava como homogêneo, linear e vazio). Da mesma forma, na França, no fim dos anos 20 contra a história positivista, dos acontecimentos, política, nacional e superficial, alguns historiadores voltaram-se na direção de uma história econômica e social, em busca de profundidades e de temporalidades rereguladas por outros ritmos, além da simples sucessão linear dos eventos políticos. Mais profunda, mais ampla, conforme os ciclos, ela era, em suma, mais verdadeira. Esta também deveria ser uma maneira de responde àquilo que Maurice Halbwachs sublinhava, então, como "o ritmo de uma vida social cada vez mais acelerada"."

Posteriormente, apesar da catástrofe da Segunda Guerra Mundial, a impossibilidade, sem dúvida, de enfrentar aquilo que havia acontecido, as estratégias de esquecimento, a utopia revolucionária, as esperanças de transfomar a sociedade, a reconstrução, a modernização, a planificação, a competição, o confronto leste-oeste, os progressos econôrnicos, técnicos, as rápidas transformações, em resumo, a aceleração da aceleração da história e do tempo, são fatores que concorrem para manter operacional ou mesmo para relançar o regime moderno de historicidade e os hinos ao progresso: "o futuro radiante", socialista, o "milagre alemão", capitalista, les Trentes Glorieuses francesas. Pouco a pouco, todavia, o futuro iria ceder terreno ao presente, que ia adquirindo cada vez mais espaço, até parecer ocupá-lo inteiramente. Entra-se, então, no tempo do presentismo.

\section{O PRESENTISMO}

Eis, aqui, alguns pontos de refererência, sobretudo literários, para auxiliar o cerco a este fenômeno maciço que fornece ao século $X X$ sua fisionomia própria. Contra o passado, que é também a morte coloca-se na frente a vida e o presente. Concernem a esta larga corrente, primeiramente, as Considérations intempestives (1874) de Nietzsche, mas, também,L 'immoraliste (1902) de Gide ou a Hedda Gabler de Ibsen ou, ainda, as reflexões dos anos 30 de Valéry sobre ou contra a História.' Se ela deseja responder ou escapar da "falência da História", a história, mesmo profissional, deve, então, provar que o passado não é a morte, que o passado não deve sufocar a vida. Faz-se necessário encontrar um modo de relação entre o passado e o presente, de modo que o passado não pretenda servir de lição ao presente, sem que ele seja, por isto, condenado 
ao vazio. A insistência dos primeiros Annales sobre a indispensável pre ocupaça com o presente adquire, também, seu sentido, parece-me, cor relaçáo a este contexto intelectual. Sobre um outro registro, esta refle xão desiludida de T.S. Eliot, testemunha o expansionismo do presente "In our age [...] there is coming into existence a new kind of provincis lism which perhaps deserves a new name. It is a provincialism, not o space, but of time; one for which [...] the world is the property solely o the living, a property in which the dead hold no shares". "Os mortos nâ mais possuem seu lugar ou, até, nấo possuem mais lugar. A morte, ser demora, tornar-se-á obscena.

La Nausée de Sartre, publicada em 1938, fornece um outro índice Roquentin, o narrador, escreve um livro de história. Ele prepara, com efei to, uma biografia de marquês de Rollebon (que se parece com Talleyrand) Mas, um dia, rapidamente, ele se vê impossibilitado de continuar, pois de repente, impós-se a ele, como uma evidência tangível, o fato de qu havia apenas "o presente, nada mais que o presente". O presente er "aquilo que existe, e tudo que nāo cra presente nāo existia. O passad não existia. De modo algum". "M. de Rollebon acabava de morrer pel segunda vez". Assim como as coisas são aquilo que elas parecem e qu por detrás delas nāo há nada, o passado não é nada. Vinte e cinco ano mais tarde, o mesmo Sartre escreveria Les Mots, que começa assim: "N Alsácia, por volta de 1850 , um professor primário sobrecarregado de cri anças, consentiu em tornar-se merceeiro [...]".

A crítica do progresso. Otopos, com certeza, nāo é novo, mas pode se notar, aqui, sua reativação e seu deslocamento por Lévy-Strauss en seus imediatamente famosos Tristes tropiques (1955). No contexto di descolonização, ele propunhá uma versão renovada do bom selvagem Sua defesa apaixonada de Rousseau e sua crítica à concepção estreita de progresso nas sociedades modernas acabavam em uma meditaçâo sobr este mundo que tinha "começado sem o homem e terminaria sem ele" A antropologia deveria, antes, conceber-se como "entropologia". No: anos seguintes, o selvagem tornou-se moda: nós nos servimos do "pen samento selvagem", analisamos o "pensamento mítico", valorizamos ؛ selvagem contra o Estado. Mas houve, também, reformas $\mathrm{c}$ fugas ao tem po dos selvagens.

O slogan "esquecer o futuro" é, provavelmente, a contribuiçăo da: sixtiex no fechamento extremo sobre o presente. As utopias revolucio. nírias, progressistas ou futuristas em sua origem, deviam operar dentre de um horizonte que quase não ultrapassava o círculo do presente: "Tudo imediatamente!" diziam os muros de Paris, em 1968, pouco antes de st 
escrever: "No future" Vieram, com efeito, os anos 70 , as desilusôes, 0 desvio da idéia revolucionátia, a crise econômica de 1974 e as respostas mais ou menos desesperadas ou cínicas que, todas, em todo caso, apostam no presente e somente nele. Nada além. Mas isto nâo cra, exatamente, o carpe diem dos homens da Renascença.

Nesta progressiva invasão do borizonte por um presente cada vez. mais inchado, hipertrofiado, está claro que o papel motor foi representit. do pela rápida extensīu e pelas exigências cada vez maiores de uma sociedade de consumo, onde descobertas científicas, inovaçôes técnicas, busca de lucros, tornam obsoletas as coisas e os homens, cada vez mais rapidamente. A midia, cujo extraordinário desenvolvimento acompanhou este movimento que é, no sentido próprio, sua razão de ser, procede da mesma forma: produzindo, consumindo, reciclando, cada vez mais rápido, palavras e imagens.

Passou-sc, portinto, em nossa relação de tempo, do futurismo para o presentismo: para um presente que é, para si mesmo, seu próprio horizonte. Sem futurc e sem passado, ou gerando, quase diariamente, o pas sado e o futuro de que necessita cotidianamente. Desta atitude nāo faltam provas: a morte cada vez mais escamoteada, sobre a qual Aries, vindo do tradicionalismo, foi o primeiro que soube chamar nossa atençäo; a valorizaçáo crescente da juventude como tal, nas socjedades que já começavam a envelhecer; todas as técnicas de supressăo do tempo, graças ao desenvulvimento dos meios de comunicaçăo (as comunicaçóes ditas cm "tempo real"). Cada um poderia, comodamente, completar o catálogo de comportamentos: lodos tendem a uma negaçăo do tempo. Aliás, sabe-se que toda pessoa que se preze é obrigada a nāo ter "o" tempo!"

Antes de tratar das falhas, que sem demora apareceram nestc onipresente presente, vejamus, brevemente, de que maneira a historiografia profissional percebeu c respondeu (ou năo) da esta mulaçăo. Sem excessiva surpresa e de forma esquemática, pode-se observar que a resposta năo foi nem imediata nem direta. Confirmou-se a inclinaçāo da história, que contava e quastificava, a buscar outras temporalidades, com a longa duração braudeliana (oticialmente proposta para as outras ciências em 1958), até a história imóvel de Le Roy Ladurie, longe, portanto, da escuma dos dias. Na mesma direcuio, mas no nível das mentalidades, autonomizou-se uma história preocupada com a etnologia (o exótico estava entre nós e, inclusive, bavianos sido. também, selvagens). Esta história, "que se aventura do outro lado do espelho", logo se chamará antropologia histórica. Jacques Le Goff formularí seu programa e, com outros, irá ilustrá-lo.

Fora deste domínio em torno de Sciences-Po, afirma-se a história 
contemporânea que lọgo reivindicará o status de "história do presente", Com seu artigo "Le Retour de l'événement", Pierre Nora fazia, en sum a ligaçăo entre os dois tipos de história: o acontecimento, sim, mas ul outro, densamento carregado, antropologizado, onde se lêem os estratı da longi duraço. Nora observará. igualmente, "o advento rápido do pr sente historico". O historiador do presente faz surgir, conscientement o passado no presente (ao invés de fazer surgir, inconscientemente, o prs sente no passado)": "é nosso presente, por completo, que busca sua pre pria consciència de si mesmo através do novo status que o acontecimes to conquistou na socicdade industrial". "Se a focalização sobre o pre sente é certa e claramente reivindjeada, notar-se-á que o modo de ser d passado é aquele do surgimento no presente, sob o controle do histori dor. Nora sempre recusou o princípio de um corte estrito entre passado presente, com base na história moderna. Os Lieux procederāo segundo mesmo percurso. Finalmente, mas nos aproximamos da metade dos ano 80, o desenvolvimento das historias nacionais indica, certamente, um resposta diferente, mas a qual questāo?

\section{AS FALHAS DO PRESENTE}

A economia (da mídia) do presente nĩo pára de produzir e de consu mir 0 acontecimento. Mas com esta particularidadc: o presente, no momen to em que se faz, deseja ver-se como jí histórico, como já passado, voltan do-se, de algum modo, sobre si mesmo e antecipando o ollhar que a ele ser dirigido quando for completamente passado. Como se ele desejasse "pre ver" o passado, fazer-se passado antes mesmo de tornar-se completamen te presente, mas este olhar, é o seu que se the apresenta. Um presente qu é. para si mesmo, seu próprio passado, sonho de um domínio do tempo ou ainda, de sua supressăo. Um exemplo entre dezenas de outros possiveis Em 10 de maio de 1994, jornalistas entrevistam o presidente Mitterrand exatamente um ano antes do término de seu mandato. Todo jogo consisti em fazê-lo falar como se estivesse um ano adiante, como se já tivesse par tido c mesmo como se estivesse morto e enterrado, pois the imploraran que revelasse o epitatio que escollicu para si!

Simetricamente, ele é mais do que ansioso por previsóes ou por pre diçốes. Fle se cerca de especialistas, consultando-os incessantemente (4 historiador, quando solicitado, acha-se, aliás, transmutado em especia lista). Fiste presente encontrou nas sondagens seu sćsamo: projeçóes nu futuro sem alterar u presente. A resposta atual, imagem instantânea, i 
transportada seis meses mais tarde e tende, insensivelmente, a transformar-se em imagem efetiva da situaçăo scis meses mais tarde. Aquilo que você vota hoje como imagem daquilo que você votará dentro de seis meses. O que vocề já votou. A duração é reintroduzida somente na forma da série que permite traçar uma curva das sondagens. Mas até as sondagens se enganam!

Na metade dos anos 70, aproximadamente, uma outra falha aparcceu. Este presente, já inquieto, descobritt-se em busca de raizes e de identidade, preocupado com a memória e as genealogias (sabe-se o lugar ocupado pelas pesquisas genealógicas nos Arquivos), preocupado com a conservação (de monumentos, de objetos, de modos de vida, de paisagens, de espécies animais) e ansioso pela defesa do meio ambiente. Viver no país e a ecologia tornaram-se temas mobilizadores e mensageiros. Conservaçấo c reabilitação substituiram, sobretudo nas políticas urbanas, o simples imperativo de modernizaçẩo, cuja brilliante e brutal evidência até entấo năo havia sido questionada. Como se se desejasse preservar, de fato reconstituir um passado já desaparecido ou a ponto de apagar-se, sem volta.

Dois exemplos iluminam esta mudança de atitude com relação ao tempo. Touvier, o antigo chefe da milícia de Lyon, é condenado por crimes contra a humanidade. Em 1972, ele foi agraciado pelo presidente Pompidout em 1974, ele é condenado. Ora, é exatamente o mesmo Touvier. O tempo funcionou às avessas: longe de trazer o esquecimento, ele avivou, reeonsiruiu e impôs a lembrança. Em 1970, Pompidou, ainda ele (cujo vigésimo aniversário da morte foi comemorado sem grande sucesso), lança a construçăo de um novo grande museu de arte contemporânea, o grande tanque de Beaubourg, e inicia a destruição dos mercados. Daí um buraco (o "trou de Halles"), que o prefeito de Paris, um certo Chirac, acabará por preencher a seu modo. Final de 1993, Milterrand inatugura o grande Louvre, com sua pirânide de vidro, que indica uma presença bem-sucedida de arquitetura pós-moderna. O Louvre, que perdera sua tillima funçio régia com a partida do Ministério das Finanças, tornot-se, inteiramente, espaço museológico: o primeiro lugar do patrimonio universal da França (com sua galeria mercantil no subsolo).

Assim, este presente, reinando, aparentemente, sem divisão, "dilatado", suticiente, revela-se inquieto. Ele gostaria de ser seu próprio ponto de vista sobre si mesmo, e ele descobre a impossibilidade de praticar isto, Ele se revela incapaz de preeencher a distância, no limite da ruptura, que ele mesmo cavou entre campo de experiência e horizonte de espera. $O$ passado bate na porta, o futuro na janela e o presente descobre que o solo se afunda sob seus pés. Magritte poderia ter pintado. 
Três pulavras resumem estas transformaçôes: memória, mas, ta-se, de fato. de uma memória voluntária, provocada (aquela da h ria oral), reconstruida (da histótia, portanto, para poder contar sua toria); patrimonio: 1980 foi decretado ano do patrimonio. O sucess palavra e do tema (de tesa valorizaçāo, promoçáo do patrimônio) or junto com uma crise da própria noção de "patrimônio nacional"; $c r$ moraçào: de uma comemoraçio outra poderia ser o título de uma cl ca dos dez tíltimos anos. Estes três termos apontam, todos os três direçáo a um outro, que é como se fosse o seu lar: a identidade.

As comemoraçoes delinem um novo calendário da vida pública pondo-the seus ritmos e suas datas. Esta última se rende a elas e del serve, tentando conciliar memória, pedagogia e mensagens políticas intermediários. A visita ao Panthéon de Mitterrand, em 10 de mai 1981, inscreveu-se nesta perspectixa: incursão inaugural ao país dos : tos ilustres da República, a rosa na mão (Michelet tinha um tamo de o para revivificar estes lugares desertados e para se preparar para escr uma nova página na historia da França. Passou-se de comemoraçã comemoraçăo, em um ritmo que ia, ele mesmo, acelerando-se. Ti estes rearranjos en torno da memória operavam-se enquanto avan a comemoraçîs mator: aquela da Revoluçăo, que incitava a coloct ordem do dia e em questâo o fato mesmo de comemorar. O que no: leu, com o auxílio da polêtnica, um milênio capetiano em 1987, f mente autentificado por uma missa solene, na presença do presiden República. A este fogo de artifício comemorativo suceder-se-ia, in atamente, a rajada dos cinqüentenários da Segunda Guerra Mundia

Longe de ser um fenômeno apenas francês, a comemoraçăo fle ceu por todos us lugares: a Alemanhá, por exemplo, praticou-a ce mesmo ardor, desde os anos 80. Basta mencionar o quinto aniver: do nascimento de Lutero, em 1983, os 750 anos da fundaçăo de Bes em 1985, ou a inauguração (controvertida) da "Neue Wache", em lim, em 1993, como memorial central da República Federal. 12

\section{MEMÓRIA-HISTÓRIA}

Em 1974, aparecin Faire de I' histoire, dirigida por Jacques Le' e Pierre Nora, que pretendia "ilustrar e promover um novo tipo de h ria". A memóra nāo compreendia novos objetos ou novas abordag Quatro anos depois, o dicionário de La nouvelle histoire comporta entrada "memória coletiva", redigida por Nora, onde é possível ler c 
meiro esboço do programa dos "Liezx de mémoire". ${ }^{13}$ Em 1984, sai o primeiro volume dos Lienx que, partindo justamente da comemoraçăo, remonta na direçio da memória, interroga-se sobre a divisáo entre história e memória e se propóe a demonstrar que a memória também tem sua históna. Para assim proceder, faz-se necessário um instrumento heurístico: o "Jugar de memúria".

Se os historiadores sempre tiveram necessidade da memória, eles sempre desconl liaram dela. Tucídides já a recusava como não confiável: ela esquece, deforma, obedece a uma cconomia do prazer. O olho, a evidência da autópsias, prevalecia sobre o ouvido. A história científica do século XIX começou por estabelecer um corte nítido entre o passado e o presente. Foi isto o que sempre fez de Michelet um transgressor, ele que atravessou e reatravessou tantas vezes o rio dos mortos. A historia deveria começar onde cessa a memória: nos arquivos escritos.

"Entre mémoire et histoire", o texto de abertura dos Lieux partia do fluxo memorial, buscava analisar e extrair as consequêencias do ponto de vista das maneiras de escrever a história e sobre o exercício do ofício de historiador. Foi indo de um termo para outro, quase na sua repetiçăo, como se Nora buscasse uma via entre as duas, que para ele se tornou claro que a história nacional, modelo Lavisse, era, no fundo, uma memória passada pelo filtro da historia, uma memória "autêntica", transmutada em história, "no cruzamento da história crítica e da memoria republicana": uma história-memória. "Im 14 de julho", escrevia Lavisse, "à unidade monárquica sucedeu-se a unidade nacional, que se revelou indestrutivel". De onde a identilicaçâo da Revolução com a Naçāo. da Nação com a República e da República com "um regime que se possa crer definitivo". Tal era a operacaio historiográlica de Lavisse. No mais, os 27 volumes satisfaziam-se com um relato contínuo, recortado em fatias cronológicas sem surp̧resa e sem inventividade, cum indicaçăo das fontes. Dois tempos fortes sobressaiam do conjunto; o Tableau de la géographie de la France de Vidal de la Blanche e o Louis $X J V$ do próprio Lavisse.

Lavisse sublinhava, aindi, esta singularidade a respeito da história da França: a Revoluça a havia separado de seu passado, reconstituíf to cra, portanto, "questắo de erudição", de história, e não de memória. Isto legitimava o papel da história como preceptora nacional: a pietas erga patriam pressupunhá u conhecimento da pátria, $\mathrm{A}$ função, ou melhor, a missão da historia estava clara.

Com certeza, Lavisse representou um dos pontos de partida da reflexâo de Nora historiador. Foi para ele que dedicou um dos seus primeiros artigos (Lavisse, a preceptor nacional e o infatigível pedagogo da 
nação "concluída", 1962). ${ }^{14}$ A Histoire de Lavisse representou, aq! papel de laboratório. La République, o primeiro tomo dos Lieux, su com efeito, de uma leitura crítica de Lavisse, um Lavisse visto dos tidores, de onde se mostra a fabricação de uma história nacional mesno tempo que se a desmonta como memótia nacional, fazendo, tamente, o primeiro ensaio da noção de lugar de memória. Seria q suficiente partir da evidência dos "lugares-comuns" da República (as" Cores, a 14 de julho, o Panthéon...) exibi-la e questioná-la. Para ch a uma primeira definição de lugar como aquilo que é, simultaneame material, funcional, simbólico: objeto em ruína, onde o passado en tra-se retomado no presente. Mas, hoje, para Nora, a ligação com e lugares simbólicos tornou-se muito tênue: eles são como "essas con sobre a margem, quando reflui o mar da memória viva". Eles estãi mas a única relaçño ativa que se pode estabelecer com eles é aquela propôe os Lieax, uma relação de segundo grau, resultado da reativa de algo de que eles foram na história.

Para compreender o que se passa, em 1980, cntre memória e hi ria, os compromissos desta nova demanda de memória, Nora inicia tr: portando-se para um século antes quando, com Lavisse, havia apen questâo da história. 1980 vem olhar 1880 e, 1880 , refletindo este ol envia de volta a intcligibilidade sobre 1980. A aproximaçáo dos dois mentos é, por si mesma, esclarecedora: ela faz compreender que "a tória" de Lavisse ć, em seu princípio, a memória (republicana) prom da à dignidade de história, c que a exigência contemporânea de mes ria é, de fato. uma demanda da história. Ela mostra, também, que aq que se estabeleceu nos anos 1880-1890 (a síntese republicana, com santa trindade laica, República, Nação, França) está, um século dep em vias e em condiçōes de se desfazer. Desde entāo, o que acontece c cadu um destes termos se o alento do espírito republicano não mais une ou, ainda mais, se eles tendem a tomar ou a retomar sua autonon O que resta da Naçao sem a República? Será o fim da França?

A enquele dos Licux, rapidamentc, colocou em evidência uma riodizaçáo dos "avanços memoriais": por volta de 1830 (com a obr Guizot), de 1880 (com a fixaçăo dos rituais e da história republica] de 1980 (o ponto de partida da enquete dos Lieux). Acrescentarei 19 menos visível, sem dúvida, na medida em que nâo é traduzido pela : duçâo de grandes obras nacionais, retomadas ou renovadas, mas, sol tudo, por uma contestação da história oficial, uma valorizaçāo da ] mória contra a história e a busca de uma outra história, isto é, de um tro tempo historico. 
[9]4. O nome de Water Benjamin, ele que pensa entre a França e a Alemanha, é suficiente, aqui. para designar c ilustrar este momento de profunda crise do tempo, que a guerra apenas avivou. Contra o historismo, ele se esforça para construir um novo conceito de história, colocando em seu centro a nocāo de rememoraçio (Eingedenken). Forjando a noçio "atual", ele ivalia, combinando messianismo e revolução, que o tempo histórico somente nasce quando se opera "uma conjunção fulgurante entre o passado e o presente":

Desta crise do tempo, o próprio projeto de Recherche du temps perdu (do qual, alias, Benjamin foi o tradutor) é um outro indício. Ela vai concluir este livro, que deveria, justamente, escrever o tempo, "a forma do tempo", quando, na biblioteca do príncipe de Guermantes, a evidência da idéi do kempo se impôs ao narrador. Encontrá-se, ali, quase o lugar de memória. Proust fala de "lugar distante" e de "lugar atual" e, entre um e outro, a propria sensação de outrora, com a ressurreição da memória, que é a irrupça do passado no presente. Assim, madame de SaintLoup aparece para o narrador como uma espécie de lugar de memória. Năo seria eli como săo as "estrelas" nas floreslas, cncruzilhadas para onde convergem rolas vindas, pari nossa vida também, dos mais diferentes pontos? Chegavam a ela "os dois grandes lados", onde ela tinha feito "tantos passeios c sonhos". O livro acaba nesta presença física, vertical. do tempo. "O bomem, por náo possuir a extensão de seu corpo, mas, sim, de seus anos", é colocado, recorda-se, sobre muletas vivas de tempo que sĩo, "is vezes, mais altas do que os campanários". Tal qual o duque de Guermantes, vacilando sobre seus joclhos.

Proust conduziria a Bergson e suas análises de duração. Projetase, aqui, toda uma configuraçio intelectual, que ultripassit, largamente, a França. Pode-se, tambem, relacionar Charles Péguy, adversário confesso e leroz da hiskória, tal qual o encarnam Lavisse, Langlois e Seignobos. Contra a história, Péguy (cle mesmo apoiando-se em Bergson) invoca a memória. Contra o sacrossanto método histórico, ele escolhe Hugo e Michelet. Em Cho (julho de 1913) ele opōe a história "essencialmenle longitudinal" à memória "essencialmente vertical". A história "passa ao longo", isto é, "ao lado". Ao passo que a memória consiste, estando dentro to acontecimento, antes de tudo, em não sair, em permanecer e em consolidar-se em seu interior". 15 Péguy, cvidentemente, nāo deixa de pensar no Affaire: "Eu dizia, eu pronunciava, eu enunciava, eu transmitia um certo affaire Dreyfus, o affaire Dreyfus real, do qual nâo deixamos de particjpar, nós, dessa geraçăo". Em fim, a história é "inscriçâo", enquanto que a memória é "rememoraçâo". 
A estes questionamentos, os historiadores, prolissionais ou não, re podem - Lavisse deve publicar a sequência de sua Histoire $\operatorname{com} L$ ' Histôt de France contemporaine (1789-1919) publicada em 1922 -, ou, algu deles desviam-se do nacional para o econômico e social, e suas temp ralidades em profundidade.

1980. Desde metade dos anos 80 , constatou-se, multiplicaram-se sucederam-se nas livrarias as Histoire de France ou de la France. Der se ver nisto um prolongamento, mas com uma nítida mudança de direçầ do sucesso editorial que a bistoria havia conhecido nos anos 70 ? Seria tal bém, pelo menos no início, uma resposta premeditada para a crise da h toria na escola: as crianças nano mais sabiam as datas? E, inicialmente, ur resposta de direita a uma história dita de esquerda, antes que todo mun viesse em defesa justamente da República. Um primeiro balanço, feito p instituição historiográfica, da ascensão memorial e uma resposta, mais menos explícita, à interrogação de identidade? Podem, contudo, os his riadores voltar a ser os preceptores da naçĩo ou da república, mesmo al vés da televisão? Brandel, em seus últimos anos, ele que acabara, para s presa divina, de publicar a primeira parle de sua Identité de la France, consultado a fim de ocupar este magistério.

Uma rápida leitura dos prefácios destas primeiras Histories pr que o percurso infelectual mais interessante, com relação a este fenô no da memória, foi aquele proposto por Les Lieux de mémoire. Em posta à provocaçă memorial, então em plena expansāo, presentes ram as interrogacóes convertidas em questionamentos da maneira ] qual tinham sido escritas as histórias da França. Questiona-se, assim que modo, em determinados momentos-chave, o passado (mas qual sado e o que do passado?) foi retomado no presente para fazer dele passado significante. Sem jamais perder de vista que após ter segı estes escoumentos e estis retomadas do passado no presente, organ dos por uma retórica, o objetivo de Nora, claramente fixado desde o cio, foi o de voltar to hoje, a fim de tentar, assim instruído por este go desvio, melhor compreendê-lo e melhor fazê-lo compreender. Do sente para o presentc. Trata-se de uma contribuiçio para o debat forma alguma militante, mas, simplesmentc, cívica.

O"lugar", na primeira definiçăo dada por Nora, é o lugar, tal c ele ć operatoric em La Répubilique. Nos três tomos dos Lieux exist mais dois: Ponlo de partida inteiramente necessário, o tomo 1, La $K$ blique desemboca sempre em uma República que se vê como send mesma, seu proprio lugar de memória. Trata-se de um percurso $p$ nostálgico de lugares jí quase mortos ou bastante desertificidos: o 
po quase passado de uma República datada, que jấ nấo mais consegue sustentar-se sobre suas longas (e, em suma, não mais longa que isto) muletas de lempo. Existe, neste primeiro volume, a "mortalha de púrpura onde dormem os deuses mortos".

Para relançar a operação e ultrapassar o face a face $1880-1980$, seria conveniente retomar a noção de "lugar", ultrapassá-lo, propor uma concepção mais larga, mais dinâmica sobretudo, para questionar La Nation e La france. Primcira extensão: o "lugar" designará, simultaneamente, as manifestacóes mais evidentes da tradição nacional, os memoriais canônicos e os instrumentos que concorrem para sua formaçáo, como o Dictionnaire púdagogique de Ferdinand Buisson. Mostrando de que forma e em que uns e outros criam o sistema. Além dos memoriais repertoriados como tais, o "lugar" também deve permitir analisar a fundo "os blocos maciços de nossas representaçóes e de nossa mitologia nacional", "revitalizar os lugares que se tornaram comuns". Finalmente, é lugar de memória "toda unidade significativa, de ordem material ou idea], cuja voutade dos homens ou o trabalho do tempo transformou em um elemento simbólico do patrimônio memorial de qualquer comunidade"." Deixa-se o quadro do patrimonio nacional. A história, sobretudo aos moldes dos liaux, é uma história de segundo grau, e Nora a ela retorna incessantemente, uma história símbolica.

A montante de Proust, a própria expressão "lugar de memória" reenvia para as artes da memória, que conduzem na direçĩo da arte oratória da Antigüidade. A definição foi dada por Cícero: o lugar, locus, é o lugar (as peças de uma casa ou as colunas) onde o orador é convidado a ordenat as imagens das coisas que ele deseja reter. Recomenda-se-lhe escolher imagens vivas (imagines agentes). Neste sentido, os Lieux empregam uma concepchóo retórica da memória. O lugar do orador é, sempre, artificio. O mesmo acontece com o lugar, segundo Nora, que jamais é simplesmente dido: cle é construido e, até mesmo, incessantemente reconstruíds.

O que o faz o "lugar" é que ele é uma cncruzilhada onde se cruzam diferentes caminhos de memória e é, também, sua capacidade de ser, incessantemente, remodcladoc perdurar, de ser retomado e reexaminado. Um lugar de memória desocupado não é mais do que a lembrança de um lugar (por exemplo, "os gatuleses" e os "francos" depois de 1914). Sob o título "Conflits et Partages" (ver Conflits en partage), o volume I das France traz a melhor demonstraçio. O lugar "alargado" permite a invenção de novos lugares (objetos) e a interrogaçao, a novos custos, de lugares devidamente marcados como tais. A análise precisa da direita e da esquerda, o 
"desdobramento" destas duas noçoes-memória feito por Marcel Gauct onde se pode ler toda a historia moderna da França, oferece uma ilus! ção convincente. Nāo se trata, portanto, nem do inventário dos altos lu res, nem do catálogo de La Redoute, nem de uma história pós-moder nem, obrigatoriamente, da história dos "vencedores".

Partindo do espanto diante do sucesso do fenômeno comemor: vo, Nora pode, ao final de seu percurso, mostrar aquilo que ele cha "a inversão da dinâmica da comemoração". Nâo se deixa de comen rar, em nome da trilogia memória, identidade, patrimônio, mas a próp palavra muda de sentido. Primeiramente, a comemoraçấo era religi ("Paça isso cm minha memória" no momento mesmo em que ocorres Ceia já pode ser comemorada, ela inclui a ausência); nos riluais mor quicos, por sua vę, gue não depende da comemoração (o rei está m to! viva o rei), esta se torna, em seguida, por transferência de sacrali çăo, nacional, republicana e laica. Com o " 14 de julho", onde 1880,1 " e 1790 se correspondem e se antecipam mutualmente. Péguy havia s isto à sua maneira em Clio: "A tomada da Bastilha foi, propriamente, u festa, foi a primeira celebraçĩo, a primeira comemoração e, por as: dizer, o primeiro aniversário da tomada da bastilha $[\ldots] \mathrm{A}$ festa da $\mathrm{Fe}$ ração não toi a primeira comemoraçāo, o primeiro aniversário da tor da da Bastilha. A tomada da Bastilha foi a primeira festa da Federas uma Federaçäo avan la leare".'?

Mas, hoje, segundo Nora, a comemoraçāo tornou-se patrimon isto é, fragmentada ou "desnacionalizada", mesmo quando cla deseja reconhecida pelo Estado, sendo que ele próprio nắo se reconhece in em sua noçâo de patrimônio nacional. ${ }^{\star *}$ Mais exatamente ainda, é a F. pria nação que se transmuta em património (ao passo que o patrimô se compreende, atualmente, menos como um bem que se possui, do como aquilo que constitui sua identidade). "Como se a França deixa de ser uma história que nos divide, para torna-se uma cultura que une". "Neste movimento que conduz do político do cultural, Nora serva a emergência de um "nacional sem nacionalismo". Estaria a Fi ça do final do século XX prestes a tornat-se uma kultur nation, ainda a Alemanha, que pediu emprestada esta via $\mathrm{cm}$ resposta ì ausêncio unidade política, é de novo uma naçon, talvez de "má vontade", mas fato, nāo podendo lazer economia da questão do nacional? Haveri um começo de uma interessante evoluçío histórica.

l'ara permanecer na França, ter-se-ia, em todo caso, passado de t memória (repulylicana) transmutada em história, com a Terceira Repú ca e sob o magistério de Lavisse, para uma história que hoje, se existi 
seria lida e reapropriada por uns e por outros como memória, sob o aguithão do "dever de memória". Os últimos dez ou quinze anos marcaram, portanto, a passagem da "naçào histórica" para a "nação memorial".

Os Lieux, um pouco como La Recherche, terminam no livro a ser publicado, que seria a "verdadeira" Histoire de la France, tal qual ela poderia ser escrita hoje. São estes livros que se acaba de ler! Para tomar uma outra referência litcrária (e Nora possui uma tentaçăo, senão uma ambiçāo litcrúrtit. e a convicção de que literatura e história se relacionam), os Lieux também podem ser lidos como um Bildangsroman: "O que resta da República, pergunta ele, quando se the retira o jacobinismo centralizador $[. .$.$] ? O que resta da Naçâo quando se lhe retira o naciona-$ lismo $[\ldots]$ ? O que resta da França quando se the retira o universalismo? Um aprendizado de $\mathrm{si}^{\prime \prime}$. Assim termina, se é que posso escrevê-lo cum grano salis, o romance de aprendizado de Pierre Nora.

\section{OS LIEUX COMO SINTOMA}

Os Lieux foram considerados, sobretudo, como diagnóstico assentado na situação presente, como resposta a esta siluação e, também, como prognostico. Para terminar, eu gostaria de prolongar algumas de minhas observaçôes, tomando os próprios Lieux como sintoma. Eles pertencem, certamente, ao momento ao qual se dedicam a configurar. Porém, a própria maneira através da qual cles operam nos diz algo mais sobre nosso presente. Eles testemunham, com efeito, em razâo da permanente preocupaça ho historiográfica que os atravessa, esta tendência do presente a historiar-se. Näo se tratı, aqui, de egocentrismo, mas de explicitaçāo dos pressupostos do trabalho do historiador.

A exemplo da unidade nacional criada pela Revolução, que, para Lavissse, era definitiva e indestrutivel, sua Histoire se dava como a história defintiva da naçāo concluída, dirigida ao presente e ao futuro: uma espécie de klêma para sempre. Tratava-se apenas de aperfeiçoar a República, porém, nada de fundamental deveria mudar. Tratava-se, ainda, daquilo que ele gostaria de poder acreditar em 1921, momento em que redige a conclusão de sua Histoine, perseguida $\mathrm{cm}$ 1919. Les Lieux de mémoive pretendem ser uma historia do presente, no presente, que responda a uma crise do presente, se é que o presente, como sustenta Nora, "tenha-se tornado a categoria de nossa compreensão sobre nós mesmos". Se existe um momento dos Lieux, os Lieux também sāo, portanto, os "lugares" do momento ou os "lugares" para o momento. História da França 
para loje, os Lichx lambém escrevem (conscientemente) uma história nosso presentc. Resulta que, para Nora, o historiador não pode mais : este barqueiro entre passado e futuro, pontífice como Monod ou prof como Michelel, que lia no passado o futuro já advindo ou a advir e o p clamava. Se ele ainda é barqueiro, ele o é somente no interior do círcr do presente, "entre a demanda cega e a resposta esclarecida, entre a pr são pública e a solitária paciência do laboratório, entre o que ele sent o que ele sabe".

Mas este presente e o presentismo que o acompanha revelaram insustentáveis. Também a demanda de memória pode, entāo, ser intrerp tada como uma expressão desta crise de nossa relação de tempo e u। maneira de responder a isto (mas a memórin que reclamamos e proclan mos nầ é transmissăı, mas, sim, reconstruçio de um passado ignora esquecido, falsificado, cuja reapropriaçăo c mesmo reativação, ela de permitir). Un dos problemas que nos é colocado, atualmente, é o dè res belecer uma circulaçâo entre o presente e o passado, mas laubém o fu ro, sem que nos submetamos à tirania de nenhum dos três termos.

Ora, a epistemologia empregada nos Lieux, simultaneamente, ; loca, reivindica a centralidade do presente, e a contorna ou dela escal De que forma? Eazendo, justamante, da passagem do passado no preser de sua comunicaçâ, que caracteriza of funcionamento da memória ponto de partida de sua operaçăo historiográfica: converter a memón não como contetido, mas como forma, em modo de questionamento h tórico e de escritura da história. Ainda que o historiador clássico jáa meçasse a estabelecer. como fora lembrado, a nítida separação dos d (a história deveria ser tão-somente a ciência do passado e o historia um simples olho llutuandu no silêncio dos Arquivos). Ao contráric lógica dos Lieux conduz a considerar o próprio historiador como lu. de memória. Reencontra-se a figura de Michelet, mas, também, No editor dos Essais d'ego-histoire."

Globalmente, percebe-se um indício desta relaçăo de tempo di rente no movimento de retorno sobre si que conheceram, há dez anos. disciplinas, inclusive científicas, as instituiçoes e mesmo as empres repentinumente preocupadas com seus arq̨uivos e com sua história. E perspectiva e este percurso historiográficos, a disciplina histórica ta bém os conheec, notadamente como trabaho reflexivo sobre seus pr supostos e sobre suas práticas, ${ }^{2}$ mas o projeto dos lieux empurrou para mais longe, estorçando-sc para colocar, à medida do possível, : própria historiografin em seu percurso.

Sintona, ele o é também no sentido em que o lugar de memória ot 
ve sucesso: cle cetrou, rapidamente, nos hábitos e nos fatos, e mesmo na lei. Classificaçio ao título de lugar de memória da Oiympia ou do Fonquet 's! O lugar vem cm socorro do "Patrimônio Nacional", Iransbordado c ultrapassado. Concebido em um regime de históra nacional, o Patrimônio, aquele da Direção do Patrimônio do Ministério da Cultura e da lei de 1913 , de fato encontrou-se intimidado a responder às demandas de uma memória nacional fendida. OLicux poderia, ao gue parece, fornecer-the a categoria que os legisladores dì Terceira República năo puderam, evidentemente, conceber. Mas, de uma só vez, o lugar encontraya-se recuperado pelo fenômeno histórico que haviu conduzido à sua elaboração, e sobre o qual ele pretendia projetar, en troca, a inteligibilidade. $O$ insirumento cognitivo que deveria servir para cincunscrever e para melhor compreender a invasora comemoraçao, tornava-se, ele mesmo, um elemento a mais do dispositivo chamado em auxílio do Patrimônio e da comemoraçăo. 1sto prova que o diagnóstico de Nora atingiu o objetivo visado, mas corre o risco, também, de ver o projeto retornar unicamente para a atualidade e ser consumido pélo próprio fenômeno que ele auxiliou a compreendes:

Sintoma atual, os Lieux também o são na concepçño da memória que se encontra no trabalho. Suponhamos, por um instante, uma tal enquete conduzida há vinte e cinco anos. Estou convencido que o inconsciente (o lapso, o "branco", a anmésia, o deslocamento, etc...) aí representou um papel importante. A memória dos Lieux é uma memória sem inconsciente, salvo metufótico, nâo por princípio, mas de fato: eu falei de concepcáo retórica do lugar. O investigador nīo visa desalojar o impensado do ligar. mas antes, a reconstituir aquilo que o tornou pensável. De onde, talvez, uma certa dificuldade em dizer os "nāo-lugares" ou os "mius" lugares da história ou da memória nacional?

$O$ apelo â memória manifestil a crise do presentismo (os Lieux constatam esta demanda e respondem de forma crítica, propondo o "lugar" como instrumento cognitivo). Ouanto ao presentismo, assim nomeado em referência e oposiçio ao futurismo, eu ocompreendo como a cxpressăo de um profundo questionamento de regime moderno de historicidade. O futuro, o progresso e as idcologias que a ele se ligam perdem sua força de convicçâ, ainda que a distância entre horizonte de espera c campo de experiência tenha-se tomado máxima. É notável que, atualmente, a reintrodução da dimensão do futuro opere-se, principalmente, pelo desvio da preocupaça com a conservaçao: de um modo negativo. Para impedir ou, simplesmente, retardar a destruição, o empobrecimento, a pohijẹâo do nosso mundo. O sucesso da ecologia pressupôe un reconhecimento partilhado da conservaçāo, em si mesma, como valor: 
E chega 1989, que representa o 9 de novembro, com a queda : muro de Berlim e o fim da ideologia que foi concebida como a extren dade mais avançada da modernidade. Fin náo da história, mas, esta c hipótese, fim de ou forte cisâo no regime moderno de historicidade. Que dizer que, desde 1989, pode-se apreender melhor novas relaçóes de tem] que se buscam. Fim săo quer dizer que nâo exista mais futuro, mas le a reconhecer que ele é, mais do que nunca, imprevisivel (visto que 19 obriga a repensar o mundo, as regras do jogo mudaram). Do ponto vista do passado, ofim da tirania do futuro teve também como consequiê cia torná-lo opaco, torná-lo igualmente um passado, em parte, imprevi: vel. ${ }^{22}$ Não se trafa apenas da contingência, tal como $R$. Aron valoriza em sua crítica da causalidade, segundo Simiand. Este passado a reabr nem linear, nem univoco, é um passado que se irá percorrer como u campo onde se cruzam passados que foram, um dia, futuros possive alguns começaram it ser, outros foram impedidos, massacrados, ${ }^{23}$ Ind cutivelmente, os Lieux, mostrando de que forma certos "lugares" cris lizaram-se, foram remodelados, deformados, esquecidos, tomam par de um inventário crítico da história-memória da França. Atentos à to economia do passado no presente, eles propōem um modo de circulaç entre passado e presente.

1989 lumbém estabeleceu ou restabeleceu a nação em primeirop no: a naçăo causa dano ou, no mínimo problema, Morre-se muito em s nome ou sob sua proteção. É conveniente, entretanto, não negligene o fato de que a questāo naconal havia surgido antes de 1989. Estas int rogaçoes, de forma e de intensidade variadas, podem ligar-se, em par à crise do presentismo. Elas sĩo uma forma de expressão c uma for de responder a ela. Mesmo na Alemanha, ainda năo reunificada, que definia, de bon grado, como um Estado pós-nacional, os anos 1980 ram o aparecimento de várias Histórias da Alemanha, enquanto se $\mathrm{m}$ tiplicavam us colóquios sobre a identidade alemã, e mesmo quando estava convencido - dos dois lados - do caráter durável da cisáo em di Estados. Na França, os Lieux conduziam, simultaneamente, a reconl cer a presença do nacional e sua profunda transformação. Nāo se trata mais da nacâo messiànica, mas de uma nação-patrimônio, ou, ainda, uma naçio cono cultura partillsada, portadora de um nacional sem na onalismo, vivo mas pacificado, em uma França onde restava cultivar s memória como sc cultiva um jardim. É esta mutaçăo considerável $q$ os Lieux buscaram fazer ver, acompanhando-a e formulando-a. O n mento dos Lieux cra este.

Está também assegurado? Esta oscilaçăo de um modelo de naç 
para outro é assim tăo nítida e irreversível? Aquilo que acontece há seis anos no Leste, mas também no Oeste, e, mesmo na França, conduz a reabrir a questāo. Como a Alemanha irá viver como nação? E a Europa, o que será dela? Como fazer sua história? Hoje, em todo caso, os historiadores não podem elidir a questão da história nacional. Como escrevềla ou reescrevê-la, sem reativar nem a historia magistra e a tirania do passado, nem os pressupostos do século XIX, unindo progresso e naçáo, nacionat e nacionalismo? Neste ponto, os Lieux balizaram com competência e inventividade uma pista a ser retomada e prolongada em uma perspectiva resolutamente comparativa além de colocarem à disposiçăo uma noção ${ }^{2 A}$ Como escrevê-la é, também, propor uma resposta à interrogação de como circular entre passado, presente, mas, também, futuro? Mas um futuro desembaraçado de futurismos grandiloqüentes e nẩo muito monopolizado por futurólogos com postura grave e con certezas categóricas (aliás, em que se transformaram estes últimos anos?)

\section{NOTAS E REFERÊNCIAS BIBLIOGRÁFICAS}

1. Les Lienx de méncire, III, Les France, I. Paris: Gallimard, 1993, p. 11-32, O presentc artigo deseravolve uma conteréncia ministrada no Darthmoulh College, em julho de 1994, a convite dos protessorcs L. D. Kritzman e R. Stamelman.

2. A onda começoil taivez seu refluxo, ver Tzvetan TODOROV, les $A b u s$ de la méminire. Paris: Arlca, 1905.

3. CHATEAUBRLAND, Essat hixtorique, politique ef moral sur les révoiutions ancienhes et modernes, considérés dans leurs rapports avec la Révolition jrançaise., Paris: Gallimard, 1978. F. HARTOG. "Les anciens, les modernes, les sauvages ou le remps des sauvages". In: Chautebriand. Le trembìemen du temps, sob a direção de J.-C. BERCHET , Université de Toulouse-Le-Mirail, 1994, p. 177-200.

4. R. KOSILLECK. le funur passé, Contribution à la sćntintigue des remps historiques, traduzido do alemío por J. \& M.-C. Heock. Paris: Editions de l'École des Hautes Etudes en Sciences Sociales, 1990, 334p., cdiçâo alenă. 1979.

5. Tucidides pretendia transmitir nos homens do futuro um instrumento de inteligibilidade de seu proprio presente: La guerre du Réloponnèse constitúda por aquele que fora seu primciro (mas tambén último) historiador de tipo ideal.

6. M. HALBWACHS, Les cadres socimax de la momoire. 1925, Paris: Albin Michel, $1994, \mathrm{p} 262$.

7. Em várias cxasióes. Lucien Fcburc responde a Valéry, deixando para este a listória sem vida e censurando-the por ignorar a historia viva, ver Combais pour l'histoire. Paris: Ammand Colin, 1992 , p. 24, 102, 423.

8. T. S. ELIOT. On Powtry and Poets. Londres, 1957, p.69.

9. H. NOWOTNY, Le semps à soi. Gencise et structwation d'un sentiment du temps. Paris: Éditions de la Maison des Scienees de l'Homme. Paris, 1992.

10. Ver ficrire thastoin do tenips présent. En hommage à Frasçois Búdurida. Paris: CNRS Éditions, 1993, cm particular o artigo de M. TREBITSCH. 
11. P.NORA, "ie rewour de I"venement", Faire del histoire. Paris: Gallimayd, 197 1. p. $225-226$.

12. L. Frangois. "Ntaton retrousce, nation a "contre-coetr". L'Allemagne des eom morations". Le Dibat, 78 , 1094, p. 62-70.

13. La nownele histoive, sob a direfio de J. Le GOOF. R. CHARTIER, J. REV Paris. 1978 , Thatava-se, escreve Nora, de partir dos lugares, no sentido precise termo, once uma sociedade [...] deposita voluntaramente suas lembranças of recncontra como uma parte necossária de sua personalidade: Lugares topográt [...] lugares monumentais $[. .$.$] lugares simbólicos [...] lugares funcionais [...]: e$ memoriats lêm saa historia". p.401.

14. P. NORA. "E. Lavisse: son rôle dans la formation du sentinent national", Re hisiorique. juillet-septembre, 1962.

15. C. PÉGUY, Jenures compléses 111, Gallimard, 1992, p, 1176-1178.

16. P. NORA "Comment cerire l'histoire de France", Les France, op cil., I. p.20.

17. C. Péguy, oj: cri. p. 1083-1084.

18. I-M. LEVAUD, I ritopie francaise. Lswa sur le pairinoine, prelácio de Mare maroli. Paris: Menges. 1992, 180p.

19. 1. NORA wid. p. 29.

20. Lssais devo-histowe. Peris: Gallimard. 1987.

31. Ver por cxemplo, Possés reconposés. Champs et chanters de l'histoine, soba d chân the I. BOUTIER c D. JULA . Paris: Editions Autrement, 1995, 349p.

22. Sobre as desurdens do lempo histórico na Rússia, ver V. GARROS, "Dans I" URSS: de la difficulté d'écrire l'histoire", Anmales ESC, 1992, n. 4-5, p, 989-10

23. P. RICOEUR, kenps ei recit/h, Paris, Editions du Scui, 1985, p.313. B. LEPE] "Le présent de Ilispoire". In: Les formes de f'expérience. Une autre histoire si ale. Ptris: Albin Mieliel, 1995, p. 295-298.

24. Le Deberi. 78 . 1994 